\title{
LA CERAMICA, EL REFLEJO DEL SOL
}

\author{
Antonio Perla, Lcdo. en Filosofía.
}

No era la primera vez que Antonio Palacios y Joaquín Otamendi incorporaban la cerámica en sus espacios arquitectónicos. Tampoco era la primera vez que para ello contaban con Daniel Zuloaga, ocurriendo probablemente lo mismo con la casa Ramos Rejano de Triana.

El interés de Palacios hacia el color en la arquitectura y su expresión a través de la cerámica, le viene indudablemente de la mano de su maestro, Ricardo Velázquez Bosco. Con él estudió, trabajó en la cátedra de Historia de la Arquitectura, viajó a Oriente y por supuesto, por medio de él conoció a Daniel Zuloaga, con quien mantuvo una profunda amistad.

Daniel Zuloaga, insigne ceramista, y tío del igualmente insigne pintor Ignacio Zuloaga, era ya una figura sobradamente reconocida dentro del mundo del arte, cuando, en 1902, Antonio Palacios y Joaquín Otamendi se asociaban para trabajar de forma conjunta. Señalemos, únicamente como dato cronológico, que en esa fecha Zuloaga contaba con cincuenta años, mientras que Palacios tenía veintiséis. Asimismo, Daniel había realizado ya las cerámicas del Palacio de Velázquez (1883), las del de Cristal (1886-1887), la Escuela de Mi-

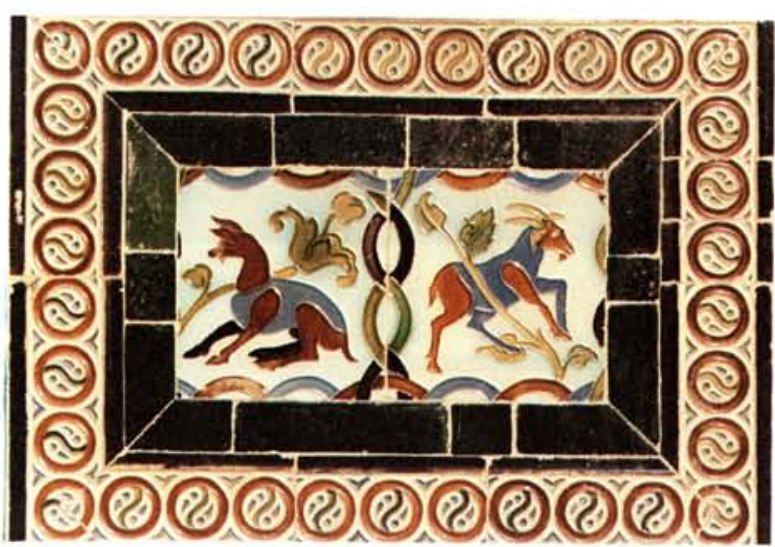

(C) Consejo Superior de Investigaciones Científicas Licencia Creative Commons 3.0 España (by-nc) nas (1886-1893) y el Ministerio de Fomento (1893-1897) para Velázquez, y habia trabajado con José López Sallaberry en el edificio de Prensa Española y con Juan Bautista Lázaro lo hacia, en esas fechas, en la Iglesia de San Vicente de Paul.

Nos encontramos en un momento en el que la cerámi$\mathrm{ca}$, en general, y la arquitectónica, en concreto, se encuentra en pleno apogeo como consecuencia, entre otras muchas cosas, de la aplicación de las teorías del color en la arquitectura, asi como de las tesis del movimiento regeneracionista. Por todo ello no nos ha de extrañar, ni lo más mínimo, el que hombres como Palacios y Otamendi no sólo mantuviesen una honda amis. tad con este ceramista, sino que además se mostrasen fervientes entusiastas y divulgadores de su obra. Sobre lo dicho, nos han quedado los testimonios escritos por ambos, en forma de cartas. Se trata de la correspondencia mantenida con Daniel Zuloaga y conservada en la actualidad en el Museo que lleva su nombre.

Daniel de Zuloaga creará normalmente sus propios diseños, sus propias composiciones, algo perfectamente lógico en un personaje que ya en su momento fue tildado con los apelativos de "gran ceramista", "gran artista" y "maestro", y no sólo reconocido en el interior de la Península, sino internacionalmente. Sin embargo, ante la fuerza arroyadora de Palacios, sus impulsos creadores, y la sutil forma de presentarlos, Zuloaga cede terreno, y asi, en las obras cerámicas que realizarán entre ambos, los diseños vendrán generalmen. te de la mano de Palacios. Hemos de tener cuatela con los juicios, puesto que no ha de entenderse este hecho como una sumisión, ni como una mera función de transposición manual, sino como una colaboración, entre arquitecto y ceramista, en la que se manifiesta un gran respeto no sólo por los conocimientos de aquél, sino por su visión e ideas estéticas. Sin esta estrecha colaboración sería imposible pensar en un resultado como el obtenido en las fachadas del Hospital de Jornaleros.

http://informesdelaconstruccion.revistas.csic.es 


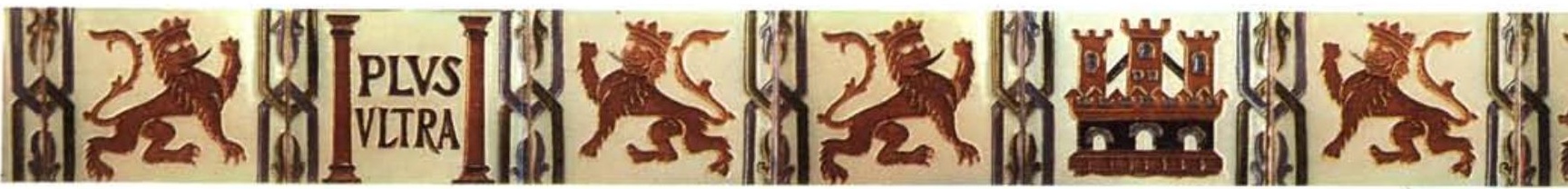

En efecto, Palacios y Otamendi se van a convertir en unos de los mayores propagadores de la utilización de la cerámica en la arquitectura, y sobre todo de la de Zuloaga. Finalmente, como sabemos, en Correos no llegó a utilizarse la cerámica en su exterior, motivado por muy diferentes causas, fundamentalmente económicas, aunque también parece que las hubo de diseño final. Del trabajo preciso y directo con Zuloaga pocas muestras nos han quedado, y en Madrid tan sólo se conservan los capiteles que realizó para la casa de $\mathrm{Ce}$ daceros 8 y 10 y el ejemplo del Hospital de Jornaleros. Tampoco se conserva la forma original de las estaciones de metro diseñadas por Palacios, en las que utilizó con profusión la cerámica de una de las mejores casas sevillanas y de las que más fama tenían, la de Manuel Ramos Rejano. A esta casa pertenecen las cerámicas del interior de Correos, asi como las del interior del Hospital.

Antes de nada, ha de estructurarse también el estudio histórico y el análisis, como el estudio de la interven. ción en dos fases: una que es la correspondiente al exterior y que a su vez se subdivide en los paneles de azulejo del friso superior y las enjutas realizadas con un mosaico de azulejos o "trencandis"; $y$ la otra parte que es la que se refiere a la cerámica de los zócalos interiores.

\section{Exterior}

Este edificio puede ser considerado como el punto culminante al que llegan arquitectura y cerámica en la búsqueda de una integración perfecta entendida con un sentido moderno y contemporáneo. Es, obviamente, el producto de un largo proceso de estudio y puesta en práctica de ciertas corrientes arquitectónicas contem. poráneas unidas al estudio de la Arquitectura Antigua. De hecho, en el edificio se logra un perfecto aligeramiento de esas inmensas superficies de piedra, a través de los brillos y el juego de color aportado por la cerámica, que recorre por lo alto todo el perímetro del edificio.
Un tema parecia claro en las mentes de Palacios y Otamendi, la necesidad y el deseo de que los paneles estuviesen realizados en relieve y no en azulejo liso. La razón parece evidente, la necesidad de un juego de luces y sombras que diesen cierto movimiento a las fachadas. Zuloaga ya había realizado elementos cerámicos en relieve para otros edificios tales como el Ministerio de Fomento, para el que creó claves enjutas y cenefas en alto relieve de bizcocho de loza; o para las fachadas del edificio de Prensa Española en las que se combinan unos mascarones en relieve con las composiciones en azulejo liso.

La solución adoptada va a ser definitivamente una solución intermedia, que consistirá en un azulejo con un cierto relieve, y que se repetirá en todos y cada uno de ellos. Los nuevos azulejos iban a ser bautizados con el nombre de "gota de agua", por el efecto de honda que presenta su superficie: dos círculos concéntricos en un espacio cuadrado.

Como ya se ha dicho, el azulejo "gota de agua", que es el que conforma el interior de los paños, tiene un pequeño relieve en forma de hondas. Esta feliz solu-

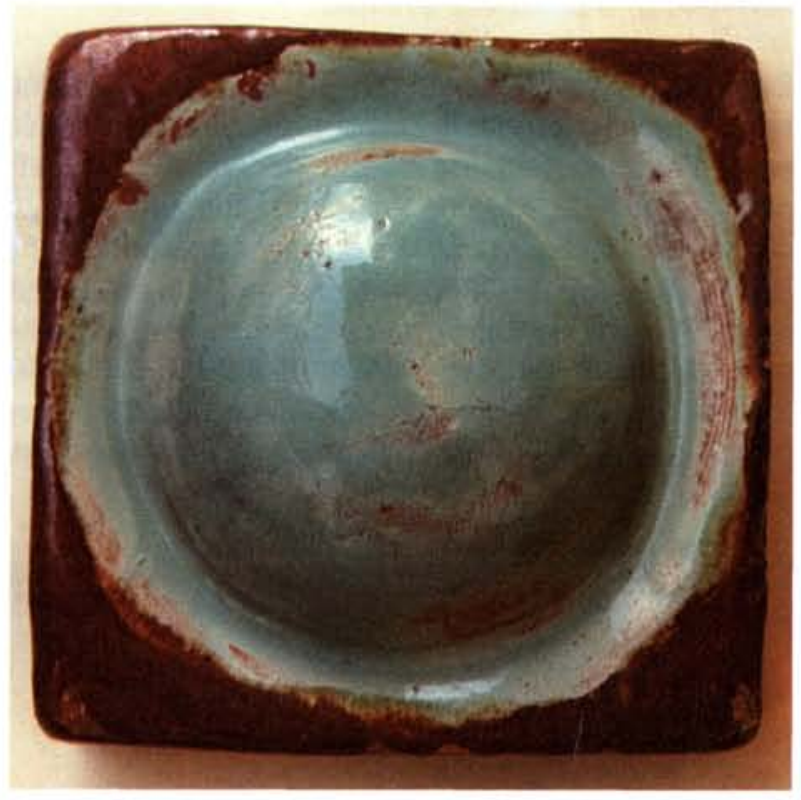

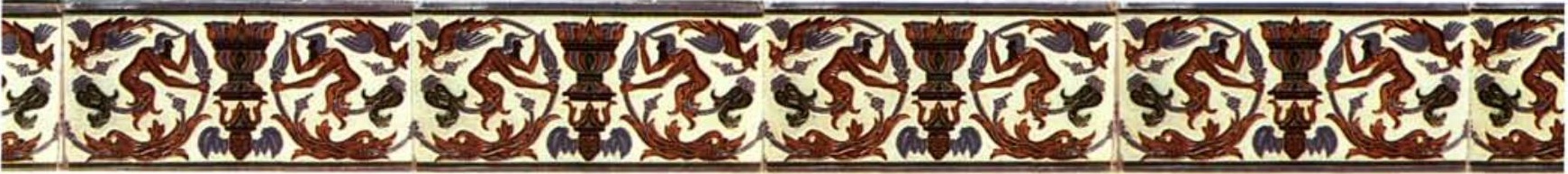




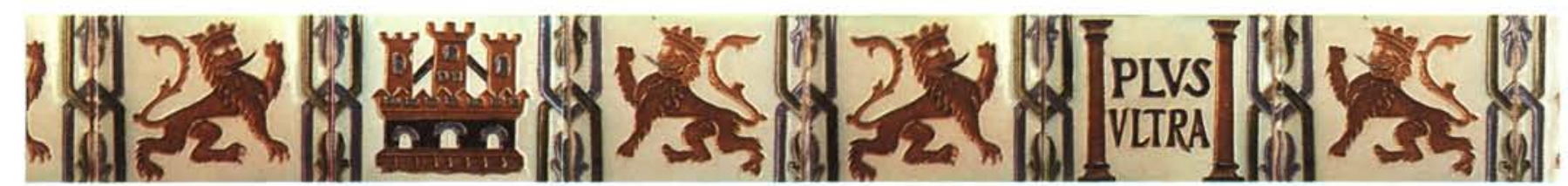

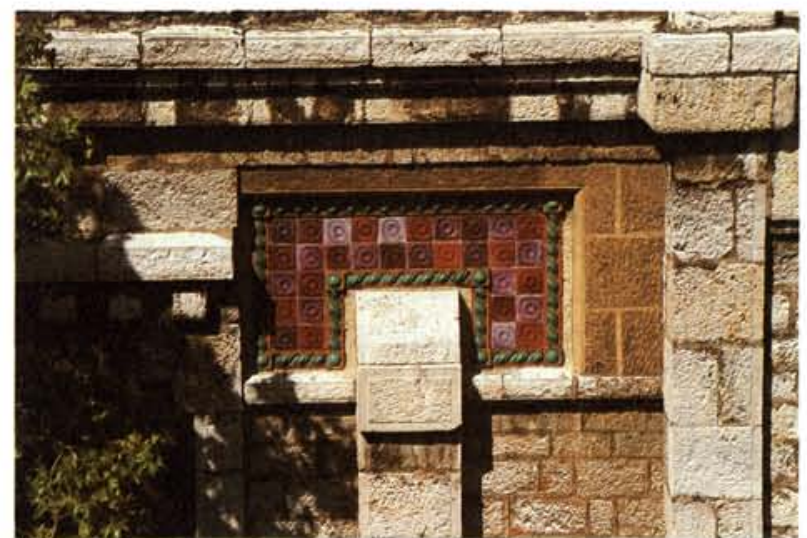

ción permitió ese efecto buscado de movimiento de la luz, ya que el ligero resalte y la disposición en círculo permiten una incidencia diferente del sol a lo largo del día. Pero ello sólo no resultaba suficiente y Palacios buscada además que el color tuviera una especial fuerza. Para ello se pensó en dos efectos conjuntos; alternar en forma de ajedrezado azulejos con diferente color y proporcionarles el brillo del reflejo metálico. Asi se llevó a cabo, utilizándose cuatro bases diferentes de color: una blanca estannifera; marrón, de hierro y manganeso; otra verde de cobre; y por último una azul de cobalto, todas ellas en forma de esmaltes opacos con una base fundamentalmente de estaño como elemento opacificador y óxidos alcalinos (sodio y potasio).

Sobre estas bases, las piezas Ilevan un lustre, fijo tras una tercera cocción reductora. Este lustre de carbonato de plata, está aplicado muy diluido con lo que se creó una película muy fina que permite transparentar el color del vidriado de fondo, y que además produce unos tonos y matices rojizos y malvas de gran belleza. La aplicación no uniforme del lustre y la mayor o menor cantidad de éste en cada pieza, llevan consigo una mayor riqueza cromática dentro del conjunto, obteniéndose de esta forma una gama más amplia de tonalidades y matizaciones. Así, sobre una misma base blan$\mathrm{ca}$, se consiguen desde unos lustres grisáceos hasta un malva cercano al granate, según esté más o menos diluido el lustre. Esta posibilidad cromática dentro de una misma base, fue explotada por Palacios y Otamendi, de forma muy clara en la fachada principal, en el cuerpo de entrada de la calle Maudes, en el que los paños únicamente están constituidos por azulejos de base blanca con lo que la masa de color se nos aparece como una mancha de color no uniforme que se mueve con la luz, con tonos dorados, granates y malvas.

\section{Interior}

El tratamiento cerámico de los interiores del Hospital es bien diferente al del exterior; de hecho, se trata de cerámica artístico-industrial, procedente de la casa Manuel Ramos Rejano de Triana (Sevilla). Esta casa que fue fundada en 1895, se dedicó principalmente al azulejo de cuenca y cuerda seca recogiendo, como otras, los modelos de la azulejeria tradicional, tanto hispanoárabe como renacentista y sobresaliendo por sus muy logrados reflejos metálicos.

Todos los pasillos del Hospital tenian, y tienen, un zócalo, formado por unas grecas de azulejo de $7 \times 28 \mathrm{~cm}$, flanquedas por tiras de azulejo liso y que a su vez enmarcan unos paños de un maravilloso "azulejo hidráulico", rematado todo el conjunto con una franja más ancha de azulejos con distintas representaciones. Así, en la primera planta del cuerpo principal (calle de Maudes), el repertorio de estos azulejos de $14 \times 28 \mathrm{~cm}$ es el de una serie de animales reales y fantásticos - unicornio, centauro, gamo, cabra, sátiro y oso-, mientras que en la segunda planta lo es el del Castillo y el León además de las columnas con el "Plus Ultra", todos ellos sacados del repertorio azulejero renacentista de tradición medieval, lo mismo que el variado repertorio de grecas y cenefas del total de los zócalos. Mientras que en el primer piso, el azulejo liso que contornea todo el zócalo, a ambos lados de las cenefas, es de color verde cobre, en el segundo lo es melado. En los pasillos que contornean el patio octogonal, la temática de la franja ancha superior en las paredes exteriores, es igualmente de origen renacentista, siendo la misma en los dos pisos. Los azulejos de las naves de la segunda planta son, sin lugar a dudas los más Ilamativos, ya que

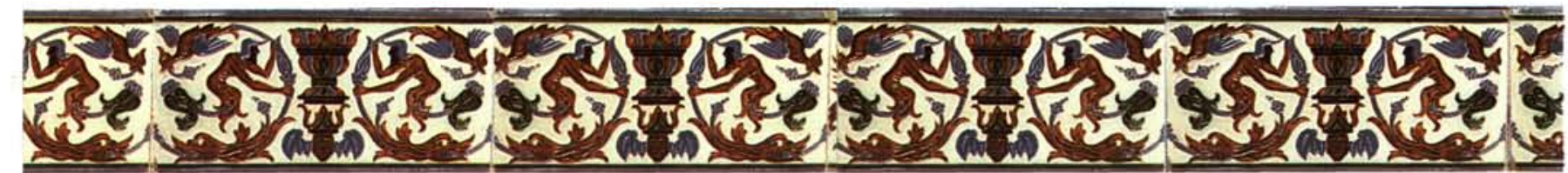




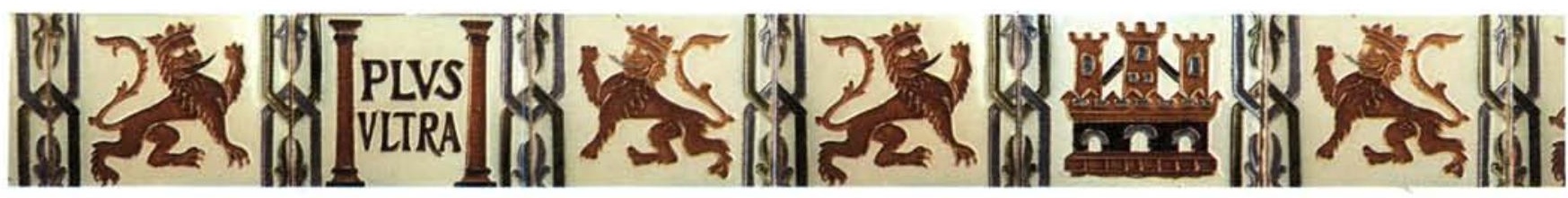

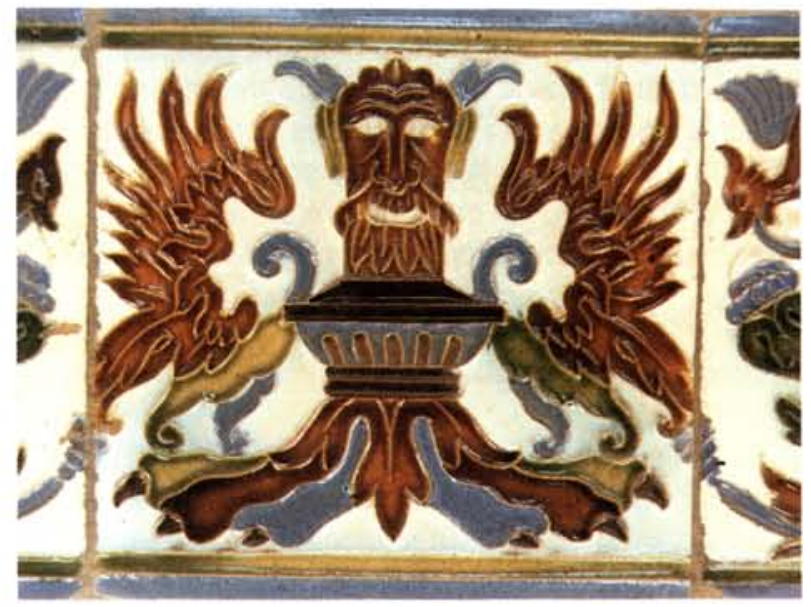

son un claro ejemplo de los maravillosos reflejos metálicos obtenidos por Ramos Rejano.

\section{Estado de conservación y actuación}

Hasta la ejecución del Hospital de Cuatro Caminos, Zuloaga había realizado toda su cerámica aplicada en pastas de loza de mayor o menor dureza. No asi la de Maudes; está elaborada en un bizcocho de barro rojo muy blando, lo que ha motivado dada su ubicación y anterior abandono el total deterioro de los paneles.

El Hospital se encontraba en un alto, de frente a los fríos de la Sierra y sus heladas, y no como está actualmente, sino totalmente desprotegido por todos lados. El estado de conservación de la mayoría de los azulejos era realmente penoso, los que no presentaban una superficie con el esmalte reventado, separado del bizcocho, estaban reventados desde el interior, y todo ello por el efecto del hielo. Una circunstancia favoreció la acción de los hielos; la pérdida parcial de las lechadas. Todos los azulejos estaban enlechados, pero con una pequeña capa muy superficial, que dado el grosor del azulejo, quedaba prácticamente en superficie. Al haber desaparecido esta película en algunas zonas, permitia la entrada de agua hacia el interior de los paños, que- dando estancada en aquellas partes donde luego la lechada le impedia la salida. A continuación venía la acción de los hielos. En las caras orientadas al norte este efecto fue especialmente virulento, pero en general, debido a la desprotección de las naves, afectó a todos los paneles. Asimismo, se ha de constatar un dato curioso, objeto de un posible estudio aislado, y es el hecho de que los azulejos con las cuatro bases - blanca, marrón, verde y azul-, los más deteriorados han sido los de base marrón, pero con una diferencia impresionante.

Otras causas han colaborado al deterioro progresivo, e incluso lo han acelerado innecesariamente, pero probablemente estas hayan sido debidas a una falta de concienciación general. Así, el abandono por el que ha pasado el edificio ha llevado consigo una falta de previsión y conservación que por otra parte probablemente tampoco la habrian tenido. Cuando se entró en el edificio, habia zonas en las que incluso se habian perdido la mitad de los paneles.

A todo esto, le hemos de sumar el elevadísimo grado de agresión atmosférica, al encontrarnos en una de las zonas en las que se alcanzan los mayores grados de contaminación de Madrid.

Por todo ello, más que una restauración de los elementos de cerámica, lo que se emprendió fue una reposición, siguiendo, si no los mismos, si semejantes criterios cerámicos y de estructuración de los paneles a lo largo del edificio. La realización de las cerámicas del exterior le fue encargada a la "Empresa de Realizaciones Artísticas BORA".

En vista del resultado dado por el bizcocho de las piezas originales, se observó la necesidad de trabajar con una pasta más resistente, con mayor grado de refractariedad, capaz de resistir el efecto del hielo sin roturas ni resquebrajamientos. Para ello se ha utilizado un barro de Valdemorillo mezclado con tierras de Segovia y una abundante cantidad de chamota de Alcañiz, aproximadamente del 40 por 100 , con mucho cuarzo.

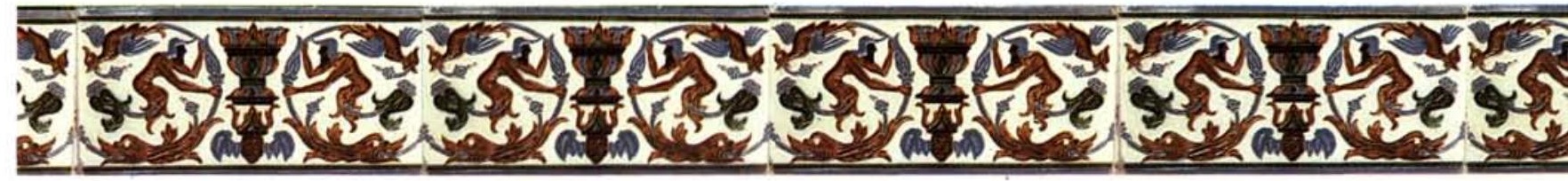




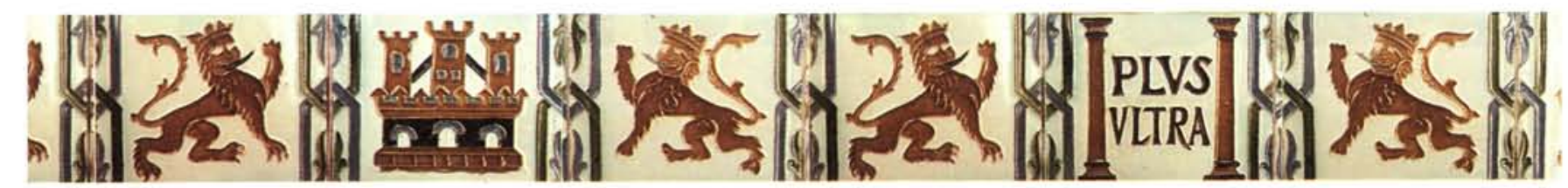

Tanto las molduras de cordón, como las bolas y los azulejos de gota de agua han sido elaborados por el sistema del apretón, que dada la cantidad de piezas a realizar, se ha llevado a cabo sobre moldes de aluminio, que ofrecen menor adherencia que los de hierro. Previamente, los moldes eran cubiertos por un desmoldeante.

Para la obtención de los esmaltes han sido estudiados los originales que con sus lógicas diferencias personales de composición, estaban basados en los tradicionales. Así, los actuales han partido de esta base tradicional, pero apoyándose en prácticas cerámicas actuales.

En la restauración del interior, dado el estado de los zócalos, se pensó en completar las faltas por medio de azulejos nuevos, elaborados como los originales, evitando la sensación de "parcheo", pero de tal forma que pudieran ser reconocidos e identificados. De esta for$\mathrm{ma}$, se ha vuelto a reproducir todo el repertorio azulejero del interior del Hospital, a excepción de las piezas de $14 \times 28$ centímetros. Con respecto a éstas, y por muy diferentes motivos y criterios, se decidió eliminarlas de los zócalos del cuerpo de Maudes. Sin embargo, las pocas piezas que en éstos quedaban, fueron trasladadas a los pasillos del octógono, completándolos con lo que en la actualidad estos zócalos muestran la organización original y su altura real. Para completar el octógono hubo que desmontar los paños más incompletos -siempre de dos en dos-y con sus piezas rellenar los huecos de los otros, mientras que sus propios espacios eran realizados con las piezas sacadas de los pasillos del cuerpo de Maudes.

Los nuevos azulejos para las reposiciones, han sido ela-

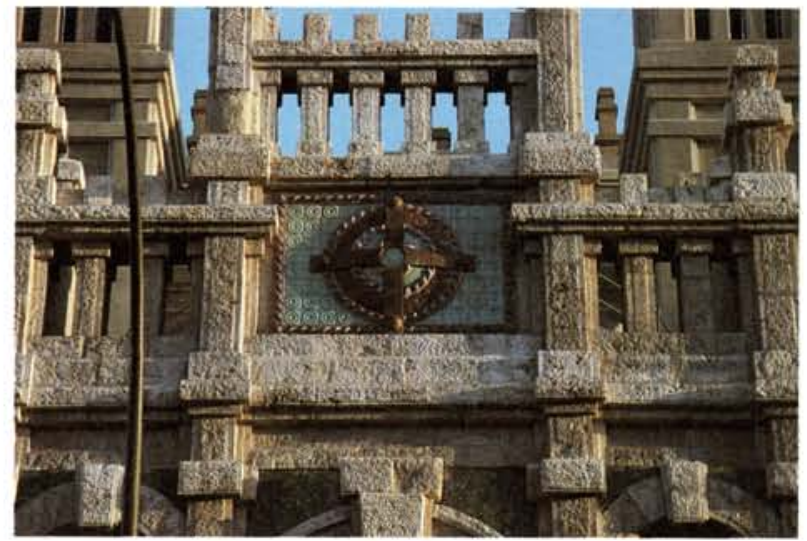

borados en una pasta preparada en el taller con barro rojo, pasta de mimbre y arena de sílice del Molar.

No sólo se han repuesto las faltas de los zócalos sino también las tabicas de todas las escaleras.

En la planta baja - la zona nueva - se ha reproducido la misma estructuración de los zócalos de los pisos superiores, pero tratados con una visión actualizada. De esta forma se han sintetizado las líneas que van conformando los paños, trazándolas con unos azulejos esmaltados en azul y en verde, colores cerámicos tradicionales, con lo que se ha pretendido establecer un elemento de transición.

Ha constituido éste, uno de los primeros esfuerzos por recuperar una parte de gran importancia en nuestro patrimonio más reciente, hasta ahora sumida en un profundo olvido y abandono, rayando muchas veces con el desprecio. Madrid ha comenzado a ser consciente de la existencia de su cerámica.

La coordinación de este trabajo ha sido realizada por el Ar-

quitecto Fernando de Castro.

Fotos: Fernando de Castro

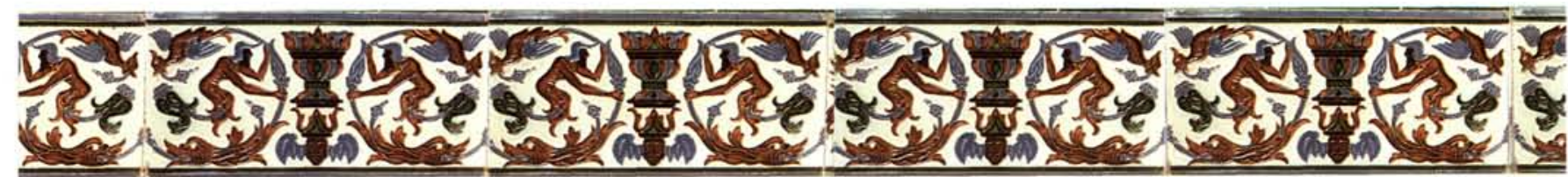

